\title{
A tentative start: evaluation of alternative forms of care for chronic users of psychiatric services
}

\author{
Stephen Colgan, Senior Registrar, Department of Psychiatry, Withington Hospital, \\ West Didsbury Manchester M20 8LR; KeITH BRIDGES, Consultant Psychiatrist, \\ Manchester Royal Infirmary; LANGLEY Brown, Director, START; and \\ BRIAN FARAGHER, Senior Medical Statistician
}

In the past decade there has been a rapid diversifcation of services provided for patients with chronic psychiatric illnesses. Although these services are thought to be beneficial for those who use them, there has been little in the way of objective evaluation. As new services begin to compete for the limited resources available, it has been recommended that they should demonstrate their effectiveness. This paper reports a small pilot study on the value of an arts based service known as START (Bridges \& Brown, 1989) which won a BBC 'It's My City' competition in 1989. It has been a popular component of the rehabilitation services of the Department of Psychiatry, Manchester Royal Infirmary since its inception in 1986.

The aim of this study was to test the hypothesis that by virtue of being an active member of START there would be a reduction in the patient's need to use other psychiatric services, thereby releasing service resources for others.

\section{START}

The philosophy of START (sheltered training in art) is to encourage patients to train and work as artists alongside practising artists and crafts people. At the time of the study there were three whole-time staff, two artists and one photographer. The project also has associate artists, volunteers, students from loca colleges, student nurses, and school pupils on work experience schemes. The service is funded jointly by the district health authority, the local authority and North West Arts. The majority of referrals to the service are from the Department of Psychiatry but an open referral procedure exists. The acceptance criteria are deliberately broad and patients are welcome to attend for as long as they wish to. On joining START, they become known as 'members' of an arts centre, which fortuitously serves to direct attention away from illness to more positive aspects of their lives and offers a sense of belonging. The members of START can be involved in a broad variety of craft disciplines and undertake paid commissions from local institutions, i.e. hospital, schools, hostels, day centres, as well as commercial clients, e.g. pubs, shops and restaurants.

\section{The study}

All current members of START who had been attending for more than six months and who were registered with our department of psychiatry were eligible to enter the study. We assumed that attendance for less than this time would not produce valid levels of change. Data were collected for 100 weeks before and after commencing with START. At the time of the study the only systematic source of information available was the patients case record held by the Department of Psychiatry. From this record information was collected on the hospital diagnosis, duration of admissions to the in-patient and day hospital facilities, the number of out-patient appointments and the number of referrals to other services for help (e.g. social services, clinical psychologists, CPNs, etc.).

\section{Statistical analysis}

The data were found to follow non-normal distributions, so statistical comparisons were made using the nonparametric Wilcoxon paired-samples rank sum test with a conventional $5 \%$ significance level. The summary statistics presented are medians and their $95 \%$ confidence limits: because of a preponderance of zero observations, the median differences are not all mathematically equal to the differences in the medians. Where membership of START had been for less time than 100 weeks the data were multiplied by the appropriate factor to create a common baseline of 100 weeks for the statistical comparisons.

\section{Findings}

At the time of the study there were 47 members of START. This study was based on 26 (18 males, eight females, mean age 45 years, range $38-48$ ) who were registered with the Department of Psychiatry and had been attending START for at least six months. Of these 26 , seven had a diagnosis of schizophrenia, 16 of depressive illness and the remainder had a 
TABLE I

Utilisation of services in the 100 weeks before and after commencing START (medians and $95 \%$ confidence limits)

\begin{tabular}{lccc}
\hline & Before & After & Change \\
\hline $\begin{array}{l}\text { Number of out-patient } \\
\text { appointments }\end{array}$ & 8.1 & 7.9 & 0.3 \\
Total weeks at & $(5.5$ to 11.2$)$ & $(5.5$ to 10.5$)$ & $(-2.5$ to 3.5$)$ \\
day hospital & 25 & 0 & 25 \\
Total weeks & $(12$ to 43$)$ & $(0$ to 0$)$ & $(12$ to 43$)$ \\
as in-patient & 8.0 & 0 & 6.8 \\
Number of referrals to & $(2$ to 12$)$ & $(0$ to 0$)$ & $(2$ to 12$)$ \\
other professionals & 6.0 & 0.4 & 5.3 \\
& $(4.5$ to 7.5$)$ & $(0$ to 1$)$ & $(3.6$ to 6.5$)$ \\
\hline
\end{tabular}

mixture of personality disorder and substance abuse. The other 21 members were not eligible for the study as six had been attending for less than six months, three did not have adequate records and 12 were not registered with the Department of Psychiatry in Central Manchester. Each patient acted as their own control, comparing utilisation of resources before and after engaging with the arts team.

The changes in the utilisation of services are shown in Table I. It should be noted that the data regarding the use of services before and after commencing at START are an aggregate of what could be several illness episodes. The small fall in the median outpatient appointments from 8.1 (range 1-30) to 7.9 (range 0-21) was not significant. Before START, the median number of weeks at a day hospital and as an in-patient were 25 (range $(0-100)$ and eight (range 0-36) respectively; after commencing with START no patients were readmitted to the day hospital and only one patient required readmission to the inpatient unit, spending just under nine weeks there. Over the same period, the median number of referrals to other professionals fell from 6 (range 1-12) to 0.4 (range 0-16). These last three changes were all significant. The study sample was too small to allow meaningful analysis by diagnosis.

\section{Comment}

As the study is based on only a small number of patients, the results should be treated with caution and not be generalised. The evaluation of our data, however, used conservative statistical tests, which tend to underestimate statistical significance. This would suggest that the changes observed in this study were unlikely to have occurred purely by chance and thus warrant serious consideration.

The study did not give us any information on patients who were referred to the service but who did not attend nor did it provide any data on consumer satisfaction. However, the reduction in the use of day hospital and in-patient services by these people once they attended START is an interesting finding and indicates that the development of this popular arts based service may have freed places in our heavily utilised day hospital and in-patient services. This has supported the day hospital's current policy of focusing upon acute illnesses and allowed extra places to be available for those who required care in these medical settings. Our results also suggest that the provision of this form of day care may have a role in reducing the risk of relapse requiring admission to hospital.

Despite its limitations, this brief audit appears to show that the development of services specifically for the chronically mentally ill can result in a gain of resources elsewhere in the system. This must represent a considerable benefit and cannot be ignored by managers of services for these types of patients. Additionally, it appears that these people gain a lot of personal benefit and much prefer it to longterm care in hospital settings. This is illustrated by the following comments from Joan, a 26-year-old woman with troublesome auditory hallucinations.

Joan attends the textile department at START where she is well-known and liked. On many days Joan is too preoccupied by her symptoms to work at her art but enjoys the company and support of the other members. At other times she is able to produce creative embroidery of such a high standard that it has been exhibited and sold. Joan stated that the completed work gave her a great feeling of personal satisfaction and the compliments the work receives from family and friends greatly boost her self-esteem. She emphasised that the informal atmosphere and the sense of belonging to 'a large family' are important to her as is the lack of health professionals whose presence reminds her of her illness. She regards the security of being able to be a member of START for as long as she wishes as being vital to her well-being and greatly values the trust and friendships that have evolved. In contrasting START with her previous 
attendance at a day hospital, Joan was critical of some authoritarian attitudes she had experienced. She added that the hospital routine combined with the rapid patient turnover prevented meaningful relationships from being developed. Prior to becoming a member of START Joan had numerous admissions to the day hospital. She blames her repeated relapses on having no friends and lack of purpose to her life. While not being free of symptoms since she became a member of START, Joan feels that her quality of life has greatly improved and she has not required further admissions to the day hospital.

\section{Reference}

Bridges, K. \& Brown, L. (1989) Psychiatric patients work alongside artists on prize winning project. British Medical Journal, 299, 532.

\title{
Measuring levels of behavioural disturbance in long stay patients
}

\author{
Dominic BeER, Senior Registrar, Training Rotation, Medway Hospital, Gillingham, \\ Kent ME7 5NY
}

Large mental hospitals are gradually being emptied. Patients return to the community. But often their prospective carers have little idea of what to expect when they arrive. Hospital staff often cannot give information regarding how disturbed patients might be.

To some extent this ignorance is a calculated part of the process whereby ex-patients become 'clients' and members of the local community, that is 'normalisation'. Community carers initially may not wish to identify problem behaviour, but when such behaviour subsequently occurs, there is unease.

In order to help bridge this communication gap and to investigate simple methods of determining disturbed behaviour, 45 in-patients were studied at a mental hospital (Bexley Hospital, Kent). Patients had previously been allocated probable community placements pending discharge. Preparations for discharge were already under way at the time of the study. The study therefore provided an opportunity to assess a survey tool which could be used easily where staff and facilities for research may be sparse, and to see if ward team's judgement regarding patients' placement was associated with patients' level of disturbance.

\section{Survey}

Levels of behavioural disturbance were observed for four weeks. Criteria for inclusion were: patients had been in hospital for more than one year; they were under 65; they were from one Health District (Lewisham and North Southwark); and, patients were not suffering from senile dementia or alcoholrelated brain damage.

The survey was based on one used at Springfield Hospital. When compared with other surveys, it differed in its particular focus on behavioural disturbance. The WHO/DAS (WHO, 1988) is a Disability Assessment Schedule. Similarly REHAB Rehabilitation Evaluation Hall and Baker - (Baker \& Hall, 1983) covers more general measures of function. The Nurses' Observation Scale for Inpatient Evaluation (NOSIE) (Honigfeld \& Klett, 1965) rates 80 items of general behaviour. 